\title{
Factores determinantes en la eficacia del Viral Mobile Marketing
}

\author{
Guadalupe Aguado Guadalupe ${ }^{1}$ \\ Universidad Carlos III de Madrid \\ Alberto GarCía GARCíA ${ }^{2}$ \\ Universidad Complutense de Madrid
}

Recibido: 5/12/2014

Aceptado: 17/02/2014

\begin{abstract}
Resumen
El presente trabajo tiene como objeto de estudio el análisis de los factores que son determinantes en la eficacia del Viral Mobile Marketing. Se abordan los efectos de la personalización en la captación de la atención en un entorno considerado privado, para lo que se consideran factores como la confianza en la red de contactos, la viralidad en nanonichos y el valor de la recomendación identificada. Se profundiza en los elementos que contribuyen a lograr la escalabilidad en la relación de las empresas con los usuarios a través de sus estrategias de marketing, con especial atención a la viralidad, multidireccionalidad, socialización e influencia del marketing relacional. Al tiempo que se estudian las variables de geolocalización que influyen en la omnipresencia de la marca. Todo ello permite observar una evolución de la comunicación one-toone a la comunicación one-to-world, donde el tráfico multidireccional a través de redes de contactos de emisores y receptores es determinante para provocar el efecto viral en la audiencia digital.
\end{abstract}

Palabras clave: viralidad, movilidad, escalabilidad, geolocalización, ubicuidad.

\section{Determining factors in the effectiveness of Viral Mobile Marketing}

\begin{abstract}
This objective of this study is to analyze the factors determining the effectiveness of Viral Mobile Marketing. It deals with the effects of personalization on grabbing attention in an environment considered private, taking into account factors such as trust in the contact network, virality in nano-niches and the value of identifiable recommendation. The analysis delves into elements that contribute to achieving scalability in the relationship of companies with users through marketing strategies with special attention to virality, multi-directionality, socialization and the influence of relational marketing. At the same time, the geo-localization variables influencing in brand omnipresence are examined. All of the foregoing allows us to observe an evolution from one-to-one communication to one-to-world communication, where multidirectional traffic through contact network emitters and receivers is decisive in producing a viral effect on the digital audience.
\end{abstract}

Keywords: virality, mobility, scalability, geo-localization, ubiquity

\footnotetext{
1 Guadalupe Aguado Guadalupe es Profesora de la Universidad Carlos III de Madrid. maguado@hum.uc3m.es

2 Alberto L. García García es Profesor de la Universidad Complutense de Madrid. algarci@ucm.es
} 


\section{Introducción. Objeto de estudio y metodología}

En el momento actual, los datos de mercado reflejan que la tendencia en el campo de la comunicación viene marcada por la movilidad. Según recoge el Informe Forrester 2013, el acceso a Internet en movilidad ha pasado del 57\% en 2009 al 82\% en 2012. De manera que ocho de cada diez internautas acceden a Internet desde el móvil. Según el informe Global Wireless Matrix de mayo de 2013, el uso de minutos al mes de voz por suscripción era de 901 en los Estados Unidos y de 107 minutos en la media europea. Además, la previsión que nos aporta el Forecast: Mobile Advertising, Worldwide, 20102017, indica que todas las regiones del mundo experimentarán un fuerte crecimiento en el gasto de la publicidad móvil.

Según datos de Nielsen Global Smartphone Insights 2012, a la pregunta de con qué frecuencia se reciben anuncios móviles en los teléfonos, las respuestas indican que la percepción - puesto que no es un dato objetivo, sino que es valorado a partir de la apreciación del usuario- es de al menos una vez al día, mayoritariamente en todos los países estudiados, salvo en India, donde perciben que les llega menos publicidad a través del móvil ya que el porcentaje más alto sólo alcanza la categoría de semanal. Profundizando en dichos datos, se deduce que los usuarios empiezan a acostumbrarse a recibir publicidad a través del móvil de manera continua y frecuente. A ello, según Cisco's Visual Networking, se une una clara evolución en el volumen de datos que se consumen a través de los teléfonos móviles, reafirmando la necesidad de establecer estrategias específicas de comunicación de las marcas para este tipo de dispositivos.

La evolución del mercado y usos del público ha llevado a que la movilidad merezca la atención por sí misma en tanto que se ha considerado un elemento esencial para la eficacia de determinadas acciones de marketing (Holmes \& Novikov, 2008), siendo merecedoras de estudio las características del marketing móvil, tales como la personalización, la individualización de contenidos, el grado de respuesta y el coste (Kavassalis, Spyropoulou, Drossos, Mitrokostas, Gikas, \& Hatzistamatiou, 2003) (Scharl, Dickinger \& Murphy, 2005). A lo que se une la ubicuidad, inmediatez, interactividad, rapidez, adaptabilidad y viralidad.

Para dicho análisis no se puede perder de vista la aportación de estudios previos como el de Roushkoff (1994), en su libro Media Virus. En el mismo se señala que si la publicidad (entendida metafóricamente como virus) alcanza a un usuario susceptible, ese usuario se encontrará infectado y entonces podrá infectar a más usuarios susceptibles.

Evidentemente la importancia que ha ido adquiriendo la viralidad a través del móvil ha merecido la atención de autores como Wedemann (2007), quien ha definido el Mobile Viral Marketing como el marketing que, a través de técnicas de comunicación y dispositivos móviles, confía en el consumidor como elemento primigenio para transmitir el contenido viral a otros consumidores de su esfera social y, a su vez, animar a estos contactos a transmitir dicho contenido a otros usuarios. Atención, igualmente, ha merecido el análisis del comportamiento del consumidor, así como el lugar y momento de entrega de información (Ktoridu, Eparninonda \& Vrontis, 2007). Destacable en este sentido es el estudio de Palka, Pousttchi y Wedemann (2009) sobre las motivaciones 
de los consumidores a la hora de optar por estrategias de Mobile Viral Marketing. A lo que se une el análisis de los llamados Alfa Users o Hubs, términos con los que se identifica al miembro más influyente de determinado círculo social, y que equivale a lo que se ha denominado grupos de aspiración (Baena Graciá, 2011), es decir grupos de los que les gustaría formar parte a una gran mayoría. En dicho contexto en el que el propio consumidor se convierte en canal de comunicación, no puede perderse de vista la reflexión de Kaplan y Huenlein (2011) cuando matizan que en una campaña de marketing viral hay que dar el mensaje correcto a los mensajeros correctos en el entorno adecuado. Entorno, al que contribuye la movilidad, en tanto que comporta que el consumidor está activo en cualquier momento y lugar, al tiempo que se posibilita una comunicación más personal. Si bien es necesario de antemano, dar por sentado que los requerimientos y hábitos de dicha audiencia, conciben al teléfono móvil como un dispositivo pensado para la comunicación personal del usuario con otros usuarios específicos (one to one) y del usuario con el mundo en general (one to world). Este primer fundamento relacionado directamente con el sentimiento de privacidad hace que el impacto dependa de la calidad del contenido, de la confianza y de la fiabilidad de las fuentes, partiendo de que cuanto más personal sea el contacto mayor será dicho impacto y teniendo presente, como señalan Gratton y Gratton (2012) que la confianza implica convertirse entre otras cosas en solucionador de problemas y guía. Dicha confianza permite las relaciones horizontales, en línea con Kotler, Kartajanya y Setiawan, quienes matizan que el auge de los medios sociales no es más que el reflejo de la migración de la confianza de los consumidores de las empresas hasta los demás consumidores (2011).

Precisamente la evolución de la movilidad, de la viralidad y de la inversión publicitaria en dicho entorno, lleva a plantear como objeto de estudio en el presente trabajo, los factores considerados clave en la eficacia comunicativa del Viral Mobile Marketing. Con ello se buscan tres objetivos: 1) apreciar en qué grado la personalización contribuye a la eficacia en la difusión del mensaje; 2) observar en qué medida la viralidad y movilidad fomentan la escalabilidad; y 3) saber si la geolocalización propicia la ubicuidad de la marca. Dichos objetivos se han marcado en atención a tres factores considerados fundamentales para que la inversión publicitaria en dispositivos móviles se incremente en los próximos años:

- La geolocalización, que aporta el usuario de manera expresa a través de aplicaciones que solicitan este permiso de poderlo ubicar.

- La posibilidad de crear mensajes hiperpersonalizados a través de la especificidad de los contenidos de distribución como está ocurriendo en Youtube y sus canales, en los que se crean listas de suscriptores que comparten intereses y temáticas y que son una fuente fiable para anunciantes.

- La viralidad, como un elemento de comunicación directa entre personas que comparten algún tipo de relación o interés. La viralidad es un elemento compartido entre las páginas web y las aplicaciones para dispositivo móvil, por lo que entra de lleno en las estrategias de comunicación de las marcas para crear campañas con éxito medible y, en cierto sentido, eficaz en lo que se refiere a valorar la cantidad de veces que se puede reproducir un mensaje en diferentes dispositivos. 
Así pues a lo largo de la investigación se abordan los efectos de la personalización en la captación de la atención en un entorno considerado privado, para lo que se consideran factores como la confianza en la red de contactos, la viralidad en nanonichos y el valor de la recomendación identificada. Se profundiza en los elementos que contribuyen a lograr la escalabilidad, con especial atención a la viralidad, multidireccionalidad, socialización e influencia del marketing relacional. Al tiempo que se aborda el estudio de las variables de geolocalización que influyen en la omnipresencia de la marca.

\section{El valor de la personalización en la economía de la atención}

Para el análisis de los factores que inciden en la eficacia de las acciones publicitarias a través de prácticas de Viral Mobile Marketing han de tenerse en consideración las estrategias que se han venido desarrollando en el ámbito de las redes sociales, que han sabido conjugar cinco funciones: comunicación, comunidad, socialización, cooperación y personalización. Esta combinación de funciones contribuye a la atracción y fidelización de usuarios, al tiempo que fomenta relaciones de confianza sobre las que se asienta la gestión publicitaria.

En dicho contexto es además necesario comprender la motivación existente detrás de la publicidad boca a boca (word-of-mouth) que funciona a modo de una recomendación. Tal y como señalan Aguado y García (2009), una recomendación hecha a un amigo acerca de un producto implica confianza y credibilidad. De manera que más allá de creer en el producto y sus características, el posible consumidor basa su compra en la confianza depositada en la persona que referencia el mensaje.

Es más, la personalización en los canales de transmisión del mensaje fomenta la economía de la atención. Ya en 1997 Goldhaber manejó el concepto de economía de la atención en un artículo publicado en la revista Wired donde proponía la hipótesis de que asistimos a la transición de una "economía de base material" donde la moneda es el dinero, a una "economía de la atención" donde la moneda es la atención. Dicha hipótesis toma fuerza en el contexto actual de abundancia de información. Todo ello en un entorno que no escapa a la advertencia de Goldhaber cuando decía "vivimos en una economía donde el bien escaso por excelencia es la atención del público".

Un indicador de esa atención es el factor tiempo. Según el informe State of the Media: The Social Media Reporte 2012, el 20\% del tiempo transcurrido ante un ordenador se pasa en redes sociales, en tanto que el 30\% del tiempo dedicado a dispositivos móviles se pasa en redes sociales. Por lo que cabe preguntarse cuál debe ser la estrategia y factores a considerar para captar la atención del público, en un entorno orientado no sólo a la comunicación sino también a la socialización de las audiencias.

Evidentemente la atención viene determinada por una necesaria conexión entre oferta y demanda, que no es ajena a factores como el contexto, la comunidad de la que

${ }^{3}$ Goldhaber, M. H. (1997): “Attention Shoppers!”, Wired Magazine, 5 (12). 
se forma parte y la experiencia. Dichos factores influyen a su vez en la delimitación de un target de más o menos interés desde el punto de vista de su comercialización a terceros, teniendo en cuenta que la atención de los diferentes perfiles no es valiosa por igual. Precisamente la segmentación de audiencias ha merecido especial atención en las estrategias de Customer Relations Management (Curry \& Curry, 2000). El objetivo es alcanzar la mayor personalización posible, lo que se refleja en nuevos modelos publicitarios, tal y como ha pasado en Linkedin (Aguado, 2014).

Pero en el entorno de movilidad, impera la velocidad y el dinamismo que conllevan que los mensajes tengan que entenderse casi sin explicaciones, por lo que se requiere de una personalización tanto en el mensaje, a efectos de lenguaje, utilidad y atención, como en canal de transmisión. Téngase en cuenta en este sentido, que en un contexto de sobreoferta, es preciso ganarse la confianza del público, que a su vez viene determinada por la propia fiabilidad que merezca el intermediario, quien ha de actuar como filtro de selección entre los usuarios y la oferta, convenciéndoles de que los mensajes seleccionados lo han sido de acuerdo a sus intereses. Esa confianza es especialmente valiosa si se trata de un entorno en el que impera la recomendación. Evidentemente en dicho contexto, en el que la comunicación es sinónimo de velocidad, es esencial la capacidad de transmisión de los primeros receptores y la confianza que merezcan. Téngase en consideración que en el caso del móvil hay tolerancia cero con la publicidad no deseada, en tanto que se concibe como un entorno privado. Precisamente por ello, el control por parte del consumidor es clave para romper la barrera de la privacidad. En dicha situación es importante contar con un incentivo que rompa la barrera y que mueva al individuo a compartir rápidamente ese contenido con sus contactos, tal y como muestran los datos que aportan KN Dimestore y SocialVibe (2011), que refleja que un $48 \%$ interactúa por el incentivo. Al tiempo que se deja de manifiesto que los anuncios que ofrecen incentivos aumentan un 38\% la percepción de marca y también favorecen las compras y las conversaciones.

Así pues, el interés en compartir ha de venir reforzado por la relevancia del propio contenido, en cuanto que ha de ser significativo y pertinente para que la intermediación adquiera un papel activo y efectivo. Si bien dicho proceso pasa por entender que en el caso de los dispositivos móviles, especialmente el teléfono, hay una concepción de espacio de comunicación privado, por lo que es preciso contar con elementos como la creación de valor. Por ello hay que plantear el mensaje desde una perspectiva de comunicación personal, en la que no haya invasión y en la que se busque compartir un beneficio o experiencia bajo la garantía que merece la recomendación de un amigo. Se da así paso a una viralidad enfocada a nanonichos de mercado, en tanto que necesita de un contexto comunicativo en el que haya afinidad en compartir y relacionarse. A ello ha contribuido la propia evolución de la viralidad, desde el ¡Pásalo! a la utilización de bases de datos gestionadas por los propios usuarios. 


\section{Efecto de la viralidad y movilidad en la escalabilidad}

A fecha de marzo de 2014, se alcanzaban 500 millones de tweets diariamente, de los que el $77 \%$ son a través de móvil; 100 horas de video son cargadas en Youtube cada minuto, y 1 billón de usuarios únicos visitan dicha página cada mes; al tiempo que 4,75 billones de piezas son compartidas cada día en Facebook. Por otra parte, en el año 2012 fueron mostrados 5,3 trillones de anuncios online según datos de ComScore. Datos todos ellos que son imposibles de alcanzar por la mera generación de contenidos, necesitando de otro tipo de factores que propicien dicho tráfico. El motivo más lógico tiene que pasar, ineludiblemente, por compartir contenidos entre usuarios, llegando a la viralidad como modo más lógico para explicar este proceso.

Las campañas virales más exitosas pueden producir 1 millón de reseñas en la web, además de su incidencia en los medios de comunicación tradicionales como la televisión y la radio. Por ejemplo, la campaña viral Kony $2012^{4}$, producida por Invisible Children Inc., generó cerca de 100 millones de visitas en 2013, con 1,3 millones de me gusta, aparte de contar con más de 2000 resultados en Google News. Su impacto fue tan abrumador que implicó la resolución por parte del Senado de los Estados Unidos para enviar tropas a la zona.

Otro ejemplo de éxito viral fue la campaña de Belleza Real de Dove $e^{5}$ que generó más de 30 millones de visitas en 10 días, o más de 15.000 personas que se suscribieron al canal de la marca en Youtube en los dos meses posteriores al inicio de esta campaña. Y esto, sin contar el éxito en las redes sociales específicas de la campaña en Twitter y Facebook.

También, fueron importantes las campañas virales Dying to Be Barbie y Before \& After Drugs: The Horrors of Methamphetamine ${ }^{6}$, que influyeron decisivamente en el aumento de tráfico en la red hacia las empresas responsables del mensaje de ambas campañas. Aquí, se comprobó la importancia de emplear las señales primarias que utiliza Google como parte de su algoritmo de clasificación: los vínculos de autoridad y el compromiso social. Estos elementos configuran, en cierta medida, el éxito o el fracaso de una campaña viral, puesto que la interacción con el contenido nunca debe centrarse en factores comerciales, sino en interés social con capacidad para ser compartido entre usuarios. De ahí, que las palabras o descriptores que se utilicen para clasificar la campaña dentro de Google van a conformar, en gran medida, la capacidad de viralización de un contenido y, por extensión, van a generar un tráfico tanto en la web como en los dispositivos móviles.

Precisamente en este tipo de dispositivos dicha viralidad está potenciada en la medida en que el tráfico se acrecienta de forma automática en atención a los contactos de cada usuario, independientemente de que sean compartidos entre el emisor y el receptor del

${ }^{4}$ http://invisiblechildren.com/kony-2012/

5 https://www.youtube.com/watch?v=WuSG0iRymbQ

${ }^{6}$ http://www.rehabs.com/explore/meth-before-and-after-drugs/infographic.html\#.VPAE1PmG-Sp 
mensaje, lo que provoca un efecto exponencial que fomenta el éxito de la viralidad. Ello ha dado lugar a una evolución comunicativa de la viralidad en la que se ha ido pasando de la comunicación one-to-one en el correo electrónico, a la comunicación one-tocontact en las redes sociales en las que el usuario provoca viralidad entre los contactos propios, hasta llegar a la comunicación one-to-world, donde el tráfico multidireccional a través de redes de contactos de emisores y receptores es determinante para provocar el efecto viral, mediante los grupos de aplicaciones de mensajería en los dispositivos móviles.

El valor del público se acrecienta en la medida en que se ha generado un espacio no sólo de comunicación sino también de socialización de las audiencias, adquiriendo un peso determinante el relacionamiento estratégico. Dicho relacionamiento ha sido propiciado en gran medida por la búsqueda de un beneficio para las partes, ya sea económico, de reputación o de círculo de influencia.

La búsqueda de dicho beneficio se ha incrementado en la medida en que el tiempo para conseguirlo se ha visto reducido, y se ha dado lugar a una comunicación multidireccional. Ello ha venido de la mano de un modelo basado en los fundamentos y objetivos que inspiran la inteligencia colectiva, definida por Levy (2004) como la capacidad que tiene un grupo de personas de colaborar para decidir sobre su propio futuro, así como la posibilidad de alcanzar colectivamente sus metas en un contexto de alta competitividad, explotando la confianza necesaria para el reconocimiento, la creación de imagen de marca, la recomendación y la creación de valor.

En dicho proceso, la inteligencia colectiva es aprovechada para fomentar que los contenidos generados por los usuarios se traduzcan en una optimización del marketing de determinados productos y marcas. Todo ello en un entorno en el que se pasa del poder de los vendedores al poder de los compradores (González; Salutregui \& Sánchez del Toro, 2004), dando lugar a un feedback que permite detectar posibles mejoras, posibilitando a las empresas construir relaciones más estrechas con sus clientes y mantenerlas a largo plazo. Ahora bien, la atención y confianza del público hay que transformarlas en valor.

En este entorno es necesario más que nunca entender a las audiencias en la lógica digital, donde se acaba la pasividad y adquiere su lugar el valor de lo compartido, de la recomendación. A ello se une la ventaja que trae consigo el móvil, gracias al cual el público (consumidor) está activo en cualquier lugar y momento. A dicha disponibilidad se suma el peso que va adquiriendo el público en la difusión del mensaje, que llega a convertirse en lo que se ha dado en llamar un prosumidor, es decir, un consumidor que produce información y contenidos con valor $\mathrm{y}$, con el valor añadido, de que es consciente de su rol en este proceso.

Las empresas deben utilizar estos recursos para incrementar su presencia en la red y poder rentabilizar los recursos publicitarios. En este sentido, la efectividad publicitaria 
en el entorno móvil pasa por poner la atención en el concepto de escalabilidad, como variable en la que se conjugan la capacidad de recursos disponibles con la capacidad de generación de ingresos. En dicha línea, hay que tener en cuenta que estamos ante un entorno en el que la escalabilidad es superior a la que se puede dar en soportes tradicionales. Si bien es cierto que hay una serie de costes fijos que se mantienen inalterables a la hora de elaborar el mensaje, los costes materiales y de distribución son más reducidos. Es más, hay situaciones en las que los costes se acercan a cero, tal y como sucede con los contenidos virales que elaboran los propios usuarios.

Dicha escalabilidad ha venido propiciada por la democratización de las herramientas de producción y de distribución (Rojas Arancibia, 2009), así como por haber dado lugar a economías de escalas virales gracias a que el valor se comparte entre los públicos, haciendo los accesos de manera directa y descentralizada. A ello ha contribuido igualmente el planteamiento de ofertar productos y servicios cuya utilidad crece a medida que también lo hace el número de usuarios, consiguiendo al mismo tiempo que cada nuevo usuario implique un coste menor de prestación de servicio.

Dicha escalabilidad ha sido fomentada por la convergencia existente en los dispositivos móviles, que han dejado de ser un accesorio para convertirse en centros de comunicación. Así pues, hoy en día dichos dispositivos tienen integrados la cámara fotográfica, la cámara de vídeo, el correo electrónico, el GPS, redes sociales, etc., elementos, todos ellos, que deben ser tenidos en cuenta a la hora de plantear estrategias de comunicación con los clientes. A ello se ha unido la omnipresencia del móvil en la vida diaria, especialmente entre los más jóvenes, lo que se ha visto parodiado en la campaña viral I Forgot My Phone ${ }^{7}$.

\section{Efecto de la geolocalización en la ubicuidad de las marcas}

Según el Informe SIE 13, elaborado por la Fundación Telefónica, existen 6800 millones de teléfonos móviles y 7200 millones de personas, lo que supone casi un dispositivo por persona. Según este mismo informe, en el segundo trimestre de 2013 se alcanzan unas ventas de 225 millones de unidades de smartphones (46\% más que tan sólo un año antes) sobre unas ventas totales de 435 millones de teléfonos móviles a nivel mundial. Estas cifras implican una base sustancial sobre la que cimentar una economía con posibilidad de acceso global e ilimitado.

Se puede decir que la penetración de los smartphones en la vida diaria facilita que las marcas siempre estén presentes, dando además la posibilidad de que el usuario sea activo en cualquier lugar y momento. A dicha ubicuidad se une la geolocalización, factor que aporta la posibilidad de hacer llegar el mensaje de marca en un contexto de proximidad al punto de compra o adquisición de servicio. Ello implica que la movilidad permite efectuar ventas personalizadas en momentos en los que no era habitual realizarlas.

${ }^{7}$ https://www.youtube.com/watch?v=OINa46HeWg8 
A ello se suma el conocimiento que permite el escaneo de código QR con el móvil, pudiendo conocer detalles adicionales sobre los usuarios. No sólo se registra la localización del teléfono, sino que además puede reconocer datos como idioma utilizado, terminal, sistema operativo, número de escaneos realizados a ese código, e incluso puede identificar de forma única la aplicación que escanea.

En dicho contexto es imprescindible contar con elementos que permitan identificar al consumidor como un elemento de análisis, de manera que se pueda llegar a establecer un comportamiento definible.

Cada vez es más frecuente encontrarse con modelos de estudio que configuren aspectos relativos a entorno social asociado, principalmente, a la geolocalización y a aspectos psicológicos. De manera que el móvil se convierte en una herramienta básica, puesto que su característica intrínseca de movilidad está asociada a la geolocalización $y$, por otro lado, la agenda de contactos es una información lo suficientemente relevante para establecer sinergias comunicativas que ayudan a conformar la personalidad y la diferenciación frente al resto.

Carasterísticas que han de ser aprovechadas por las marcas, en su afán de estar presentes en todos los aspectos cotidianos de la vida de un individuo que tengan algún tipo de relación con la estrategia definida. Téngase presente la importancia de las motivaciones psicológicas medibles, como el nivel óptimo de estimulación, que son determinantes en algunos comportamientos exploratorios del consumidor motivados por la curiosidad, la búsqueda de variedad y asunción de riesgos, y que permiten calibrar la presencia de las marcas en el entorno circundante y movible de cada individuo. Por ello, empresas como Facebook que no cuentan, en principio, con un éxito de implantación en movilidad, se arriesgan a comprar empresas como Whatsapp, que tienen en la movilidad y en el boca a boca su característica principal de éxito.

La tendencia del individuo es buscar y analizar la variedad en el entorno en el que se circunscribe, para definirse como persona y satisfacer su singularidad. Este aspecto es básico para entender las campañas virales creadas por los propios usuarios, en las que llega, incluso, a hacer públicos y virales determinados momentos, principalmente espectaculares, de su vida y convertirlos en mensaje viral, en una clara decisión irracional que puede ayudarle o perjudicarle. Por tanto, las empresas deben estimular en sus campañas esta variable que el usuario adopta para la toma de decisiones y que es definida en función de factores como el espacio de interacción o los factores atmosféricos, sentimentales, perceptivos, etc., para que las marcas puedan estar presentes tanto en aspectos internos como externos al propio individuo. De ahí la llamada onmipresencia de las marcas hacia los individuos. 


\section{Incidencia de la personalización y geolocalización en las métricas}

Los dispositivos móviles han dejado de ser accesorios para convertirse en centros de comunicación, en los que prima la disponibilidad, inmediatez y socialización. El público se ha convertido en emisor y receptor al mismo tiempo, dando lugar a un proceso de retroalimentación. Dicho contexto, caracterizado además por la personalización y geolocalización lleva a replantearse las métricas de control de usuarios. Si bien a través de la web se dio el primer paso para posicionarse más cerca del usuario como variable fundamental a tener en cuenta, frente al alcance y extensión masiva del mensaje comunicado, el desarrollo de la movilidad es determinante para impulsar una publicidad mucho más eficaz, en la que se consideren variables como la geo-segmentación y geocontextualización del entorno en función de factores ambientales, atmosféricos, etc., donde las metodologías censales tienen un peso determinante. Para ello se requiere de un seguimiento del individuo y no sólo del dispositivo, al tiempo que se hace necesario analizar los momentos y lugares más adecuados para lograr influencia, conociendo qué necesita el cliente en cada momento.

En esta línea, la investigación realizada por Mobile Squared de Adfonic revela que menos del $50 \%$ de las aplicaciones para móviles y redes están ofreciendo opciones de geolocalización. A pesar de ello, se indica que la inversión en banners para teléfonos móviles, excluyendo mensajes de vídeo y texto, de modelos de negocio basados en la geolocalización ha pasado de 202 millones de dólares en 2010 a una previsión de 1207 millones de dólares en 2014.

Dentro de las estrategias de geolocalización adaptada al móvil, los cupones se han convertido en el modelo de mayor éxito. La proliferación de dispositivos iOS y Android que cuentan con herramientas potentes de geolocalización, ha llevado a que el usuario los utilice para encontrar ofertas asociadas al entorno. Empresas como Groupon, Living Social o FourSquare están trabajando muy activamente en este sentido. Sin embargo, esta personalización asociada a la geolocalización no está todavía muy bien definida y parte de estrategias basadas en las ofertas que proponen los centros comerciales, restaurantes, etc., y que no se ajustan, de manera personalizada, a las preferencias que demanda el individuo.

Ello lleva a plantear que la medición de audiencias en dispositivos móviles debe analizar dos factores fundamentales: la audiencia y la efectividad publicitaria. En lo que respecta a audiencia hay que proporcionar información sobre el comportamiento del consumidor, incluyendo el tamaño y demografía del total de usuarios en un sitio web o una app, así como métricas relacionadas con el nivel de compromiso de la audiencia, tales como registros, transacciones o descargas. En lo que respecta a eficacia publicitaria la medición ha de ser similar a la medición en web y en offline. Esto implica el uso de parámetros de medición como la imagen de marca, el reconocimiento, la afinidad, la intención de compra, etc. Si bien, a la hora de plantear las métricas hay que tener en cuenta que el móvil no es un medio más, sino que es el reflejo de cada uno de nosotros. Por ello, es necesario medir y evaluar lo que distingue cada uno de 
los móviles en función de las aplicaciones instaladas, el modelo de teléfono, etc. Todo ello, deriva en la necesidad de buscar audiencias hiperpersonalizadas, contando con la posibilidad que brindan las plaformas móviles en lo que respecta a geolocalización y teniendo presente que el móvil es capaz de generar una cantidad ingente de datos sobre el comportamiento del consumidor y la interacción con aplicaciones y sites.

Si bien en el ámbito de las métricas existen diferentes tipos de metodologías, estándares y tecnología, no se ha llegado a un consenso definitivo, lo que con toda seguridad, ha ralentizado el desarrollo de las mediciones. Además, la evolución en los estándares tecnológicos que implementan servicios cada vez de mayor calidad y velocidad, en un mercado totalmente cambiante y en el que ha existido una guerra de sistemas operativos que no termina por cerrarse, ha hecho que las empresas tuvieran mucha cautela a la hora de invertir recursos en los dispositivos móviles. Este panorama, no obstante, parece estar cerrándose a medida que se consolidan modelos de negocio asociados a las características intrínsecas que sustentan los sistemas operativos de éxito como Android e Ios. Sin embargo, no puede perderse de vista que en la evolución de los sistemas de medición sin duda ha incidido la fragmentación del econsistema móvil, con múltiples canales y caracterizado por una gran rivalidad entre las diferentes compañías, tecnologías y plataformas.

A dichas dificultades se une el problema para identificar a los usuarios únicos. Téngase en cuenta que la publicidad digital depende de las cookies, siendo ésta una barrera tecnológica que plantea el móvil, en tanto que se impide el uso de identidades de usuarios. Hay dispositivos móviles que no aceptan cookies y en algunos de los que lo hacen, las cookies se consideran sesión dependiente, de foma que se eliminan inmediatamente después de guardarlas en la memoria del teléfono. Si los registros de servidor son bloqueados, los servicios de análisis web que utilizan registros, direcciones IP y visitantes únicos, no cuentan a los usuarios de forma correcta. Si bien es cierto que la mayoría de teléfonos inteligentes tienen un identificador de dispositivo único (UDID-Unique Device Identifier) o número de serie específico para el dispositivo, el cómo y para qué se puede usar es todavía objeto de debate.

\section{Conclusiones}

Factores como la personalización, disponibilidad temporal, geolocalización, multidireccionalidad, socialización y segmentación, se puede decir que facilitan la efectividad del Viral Mobile Marketing, en tanto que fomentan la atención del público destinatario, la geo-contextualización y geo-segmentación, la viralidad y la escalabilidad.

Ahora bien, estamos en un entorno en el que para romper la barrera de la privacidad es necesario saber gestionar las ventajas del marketing relacional, en cuanto se requiere de la no invasión y de la recomendación para el beneficio mutuo. Además, la personalización que dicho entorno supone, ha de ser aprovechada para el desarrollo de estrategias de segmentación de mercados que permitan la identificación de nanonichos, 
generando contextos comunicativos en los que haya necesidad de compartir, intereses comunes que fomentan la conversación y la retroalimentación.

Precisamente la creación de nanonichos con intereses en común, el beneficio compartido, el entorno colaborativo y la ubicuidad fomentan la viralidad del mensaje. En tanto que la recomendación en un entorno de confianza, junto al papel activo del público, que se convierte en un prosumidor y la inmediatez en la difusión del mensaje, contribuyen a la escalabilidad.

Es previsible que dicha viralidad se verá incrementada en los próximos años ante el consumo de vídeo a través de dispositivos móviles, en tanto que se rompe con las barreras que supone el lenguaje, dando lugar a un universo icónico que se basa en la capacidad de expansión y de generar sinergias afectivas a través de particularidades de las redes sociales como la valoración digital de me gusta vs no me gusta.

En dicho contexto las marcas han de tener en cuenta cada vez en mayor medida factores intra y extra- personales para poder interaccionar de manera adecuada. Téngase en cuenta que el móvil ayuda a comprender a cada individuo de manera aislada con factores como la geolocalización o la relación entre las personas que componen el círculo de vida. Ambos aspectos, son absorbidos y aprobados por cada usuario en la mayoría de las aplicaciones que se van instalando en el dispositivo móvil.

Además, ha de considerarse que la personalización del mensaje se intensifica de forma más eficaz a través de las agendas de contacto de los dispositivos. La viralización que se consigue mediante estos grupos resulta más efectiva porque son usuarios únicos los que identifican que mensajes virales de los que les llegan son interesantes para el resto de sus contactos y los distribuyen entre ellos, pudiendo incidir con comentarios que realzan la importancia del mensaje. Así, se llega a una viralización en la que el virus ataca más eficazmente porque se han seleccionado los grupos de población con cada tendencia.

La efectividad de dichas acciones vendrá condicionada por la evolución de la viralización. En este sentido es determinante el paso de los modelos one-to-one y oneto many, característicos del correo electrónico y de las redes sociales respectivamente, al modelo one-to-world, propio de los dispositivos móviles, donde el tráfico multidireccional a través de redes de contactos de emisores y receptores es determinante para provocar el efecto viral.

\section{Bibliografía}

Adform (2013): «Adform RTB Trend Report Europe», Adform, Marzo, Recuperado de: http://site.adform.com/media/27021/adform_rtb_trend_report_europe_q4.pdf

Aguado, G. (2014): «Gestión de marca en Linkedin: Evolución $\overline{d e}$ red de contactos a espacio de relacionamiento estratégico». AdResearch ESIC, 9 (9), 8-21. 
Aguado, G. \& García, A. (2009): «Del Word-of-mouth al Marketing viral: aspectos claves de la comunicación a través de redes sociales», Comunicación y Hombre, 5 , 41-51.

BAEnA, V. (2011): Fundamentos de marketing: entorno, consumidor, estrategia e investigación comercial, Barcelona, UOC.

Carmen Berné, M. \& Martínez Caraballo, N. (2008): «El Comportamiento variado del consumidor: Estado de la cuestión». Icade. Revista cuatrimestral de las Facultades de Derecho y Ciencias Económicas y Empresariales, 75, 315-336

ComsCore (2013): «U.S Digital Future in Focus 2013». Recuperado de: http://www. comscore.com/Insights/Presentations_and_Whitepapers/2013/2013_US_Digital_ Future in Focus

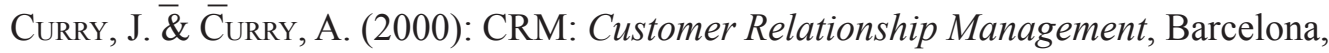 Gestión 2000.

Facebook Studio (2013). Introducing Hashtags on Facebook.

Recuperado de https://www.facebook-studio.com/news/item/introducing-hashtagson-facebook

García, A., Vinader, R. \& Abuin, N. (2010): «Parámetros y estrategias para la construcción de contenidos de televisión en movilidad». Telos. 83, 84-96.

García, M.D. (2004): Marketing Multinivel. Madrid, ESIC.

Goldhaber, M. H. (1997): «Attention Shoppers!», Wired Magazine, 5 (12).

González, J., Salutregui, J. \& SÁnchez Del Toro, J. (2004): Personalización: más allá del CRM y el marketing relacional, Pearson Educación, España.

Gratton, S.J., \& Gratton, D.A. (2012): De 0 a 100.000 Social Media: Para profesionales y pequeñas empresas, Madrid, Anaya Multimedia.

Infectus Media. Real Time Bidding Year Review Europe, 2012. Recuperado de: http:// www.infectiousmedia.com/infographic-real-time-bidding-year-review-europe/

Informes CNMCDATA de penetración de servicios finales y de infraestructuras de telecomunicación por provincias y comunidades autónomas. Recuperada de http:// cmtdata.cmt.es/cmtgraph/jsp/intro.jsp

Informe El sector TIC y de Contenidos en España, 2012.Recuperado de https://www. ontsi.red.es/ontsi/sites/default/files/presentacion_-sector_ticc_edicion_2013.pdf

Informe Estudio Mobile Marketing, 2013. IAB. Recuperad̄o de http://www.iabspain. net/wp-content/uploads/downloads/2013/09/V_Estudio_Mobile_Marketing version corta.pdf

Informe de La Sociedad en Red. Recuperado de https://www.ontsi.red.es/ontsi/ sites/default/files/presentacion_informe_anual_la_sociedad_en_red_2012 edicion_2013.pdf

Informe Mobile \& Wireless Performance in the EU\& the US. Recuperado de http://www. gsmamobilewirelessperformance.com/GSMA_Mobile_Wireless_Performance May2013.pdf

Informe Orange sobre la Sociedad de la Información. Recuperado de http://www. proyectosfundacionorange.es/docs/eEspana_2013_web.pdf

Informe del Sector de los Contenidos Digitales de España. Recuperado de https://www. ontsi.red.es/ontsi/sites/default/files/presentacion_informe_contenidos_digitales edicion2012.pdf 
Informe SIE 2013. Recuperado de http://www.telefonica.com/es/about telefonica/ $\mathrm{html} /$ publicaciones/informessociedadinformacion.shtml Informe sobre la Sociedad de la Información de Telefónica

Informe TNS SPAIN. Recuperado de

http://fr.slideshare.net/TNSspain/presentacin-del-estudio-mobile-life

Informe Vodafone sobre datos de conectividad, acceso y movilidad en España. Recuperado de http://www.vodafone.es/conocenos/es/sala-de-prensa/centromultimedia/infografias/conectividad-a-internet/

Informe Forrester 2013. Mobile Workforce Adoption Trends. Recuperado de: http:// www.vmware.com/files/pdf/Forrester_2013_Mobile_Workforce_Adoption_ Trends_Feb2013.pdf

Holmen, E. (2008): Got Recession? Mobile Marketing Goes Mainstream. Articles MMA.

Kaplan, A., M.\& Huenlein, M. ( 2011): «Two hearts in three-quarter time: How to waltz the Social Media/Viral Marketing Dance». Business Horizons 54 (3), 253263.

Kavassalis, P., Spyropoulou, N., Drossos, D., Mitrokostas, E., Gikas, G.\& Hatzistamatiou, A. (2003): «Mobile permission marketing: Framing the market inquiry». International Journal of Electronic Commerce, 8 (1), 55-79.

KToridou, D., Eparninonda, E. \& VRontis, D. (2007): «Technological and cultural aspects of the use of mobile marketing evidence from Cyprus. Ngmast 2007», International Conference on Next Generation Mobile Applications, Services and Tecnologies, 19-25.

Kotler, Ph., Kartajaya, H. \& Setiawan, I. (2011). Marketing 3.0. Madrid, Lid Editorial Empresarial.

LÉVI, P. (2004). Inteligencia colectiva: por una antropología del ciberespacio.

Recuperado de http://inteligenciacolectiva.bvsalud.org/. Consultado el 10-6-2013.

LevitT, Тн. (1960). «Marketing Myopia», Harvard Business Review, 1960, julioagosto, 45-56.

MOBILES MARKETING ASSOCIATION (2013). VI Estudio de Inversión en Marketing y Publicidad Móvil, Spain.

NIELSEN (2012). State of de Media: The Social Media Report 2012.

NoviKov, I. (2008). «Accuracy of Mobile Advertising Campaingns as Compared with Traditional Mass Media as an Advertising Medium». Articles MMA.

Palka, W.; Pousttchi, K.; Wedemann, D.g. (2009): «Mobile Word-of Mouth-A gronded theory of Mobile Viral Marketing». Journal of Information Technology, 24, 172185.

Rushkoff, D. (1994). Media Virus! Hidden Agendas in Popular Cultures, Estados Unidos, Ballantine Books.

Scharl, A., Dickinger, A. \& Murphy, J. (2005). «Diffusion and success factors of mobile marketing», Electronic Commerce Research and Applications, 4, (2), 159173.

Twitter. About. Recuperado de https://about.twitter.com/company

Consultado el 12 de marzo de 2014. 
Wedemann, D.G. (2007). «Expliring the concept of Mobile Viral Marketing through Case Study Research», in Proceeding of 2nd Conference on Mobility and Mobile Information Systems, Germany, Bonn.

Youtube. Statistics. Recuperado de http://www.youtube.com/yt/press/statistics.html Consultado el 12 de marzo de 2014.

Zuckoff, M. (2005). Ponzi's Scheme: The True Story of a Financial Lengend, New York, Random House. 